\title{
Learning Value
}

\author{
I. M. Hwang, Rui-Jun Ding, Yu-Ping Liu and Shih-Yu Chen \\ Department of Commerce Technology and Management, Chihlee University of Technology, Taipei, Taiwan
}

\begin{abstract}
Skipping Class" is a common memory of everyone’s school life. Teaching a class is the same as selling a consumer product. The perception of attending an unwelcome mandatory class is like forcing a consumer to buy an unsatisfying, non-returnable product. Thus, this generates the "Skipping Class" behavior. This research is using the "Learning Value" website to study the student's behavior of skipping class. This platform provides five primary functions: the "Skip Class”, "Fail Down”, “ABC Score”, "Guestbook", and "Sharing”. Students are able to decide whether or not to "Skip Class" via the website. The skipping class behavior risk evaluation is according to some analyses (e.g., the frequencies of class attendance and class examination, and classmates' assistance such as class notes). Fail Down is to analyze whether the student might pass the course or not at the end of this semester/quarter. ABC Score is to calculate the students' GPA in which the students may realize that skipping class is more likely to get a lower grade. Guestbook connects website users together by allowing users to share their personal experiences. Sharing introduces the different stories and practical examples of how students around the world go to school in many difficult ways, interesting writing punishment tools, and skipping class techniques. The Learning Value website is http://140.131.84.199/calculator/index_e.htm. For maximum quality, display resolution should be set at 1,024 × 768. As for technical support, the website uses IIS (Internet Information Services) as the web server and ASP.NET 3.5 as the web application framework. The database server is performed by SQL Server 2008 to organize and manage data. The webpage graphic designer used Adobe Photoshop CS6 as design tools.
\end{abstract}

Key word: Skip class, fail down, ABC score, guestbook, sharing.

\section{Introduction}

Teaching a class is the same as selling a consumer product. The perception of attending a mandatory boring class is like forcing a consumer to buy an unsatisfying, non-returnable product. Such an approach leads to a student's behavior of “Skipping Class". Students who skip classes are more likely to receive lower grades and decrease the chances to successfully graduate.

This research is using the "Learning Value" platform to study the student's behavior of skipping class. Students are able to decide whether or not to "Skip Class" via the website. The skipping class behavior risk evaluation is according to some analyses (e.g., the frequencies of class attendance and class examination, student's GPA history, and classmates' assistance such as class notes).

Corresponding author: I. M. Hwang, Ph.D., assistant professor, research fields: Internet Marketing. $\begin{array}{ccr}\text { The Learning Value website } & \text { is } \\ \text { http://140.131.84.199/calculator/index_e.htm. } & \text { For }\end{array}$ maximum quality, display resolution should be set at $1,024 \times 768$.

\section{Learning Value Website Approach}

This platform provides five primary functions: the "Skip Class”, "Fail Down”, “ABC Score”, "Guestbook", and "Sharing”. Students are able to use the website to decide the behavior of "Skip Class". The skipping class behavior risk evaluation is according to the analyses of the frequencies of class attendance, class examination, and classmates' assistance (e.g. class notes). Fail Down is to analyze whether the student might pass the course or not at the end of this semester/quarter. ABC Score is to calculate the students' GPA in which the students may realize that the consequence of skipping classes is more likely to get lower grades. Guestbook connects website users together by allowing users to share their personal 
experiences. Sharing introduces the different stories and practical examples of how students around the world go to school in many difficult ways, interesting writing punishment tools, and skipping class techniques.

As for technical support, the website uses IIS (Internet Information Services) as the web server and ASP.NET 3.5 as the web application framework. The database server is performed by SQL Server 2008 to organize and manage data. The webpage graphic designer used Adobe Photoshop CS6 as design tools.

\subsection{The Platform Structure}

The current platform for Learning Value access includes the "Skip Class”, "Fail Down”, “ABC Score”, "Guestbook", and "Interesting Sharing". The current site map of Learning Value platform is shown in Fig. 1.

The flowchart of "Skip Class" is shown in Fig. 2 to help students make decision to skip class. The skipping class behavior risk evaluation flowchart is according to the analyses of teaching information graphics, the frequencies of class attendance, and classmates' assistance.

"Fail Down" is to analyze whether the student might pass the course or not at the end of this semester/quarter according to some analyses (e.g., the frequencies of class studies and attendance, the behavior

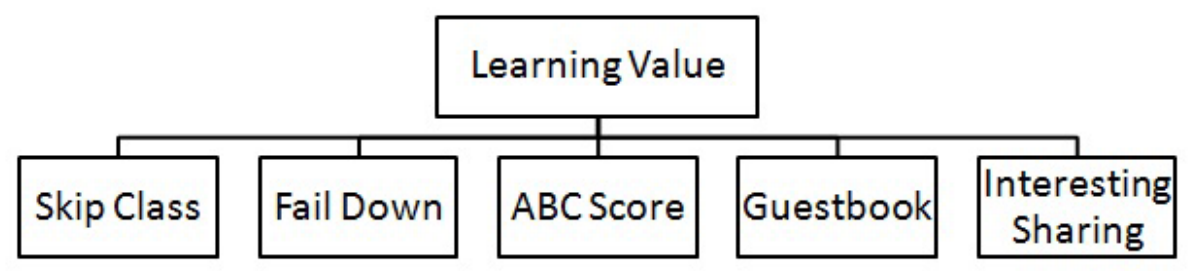

Fig. 1 The site map of learning value platform.

Learning Value

Can you skip today?

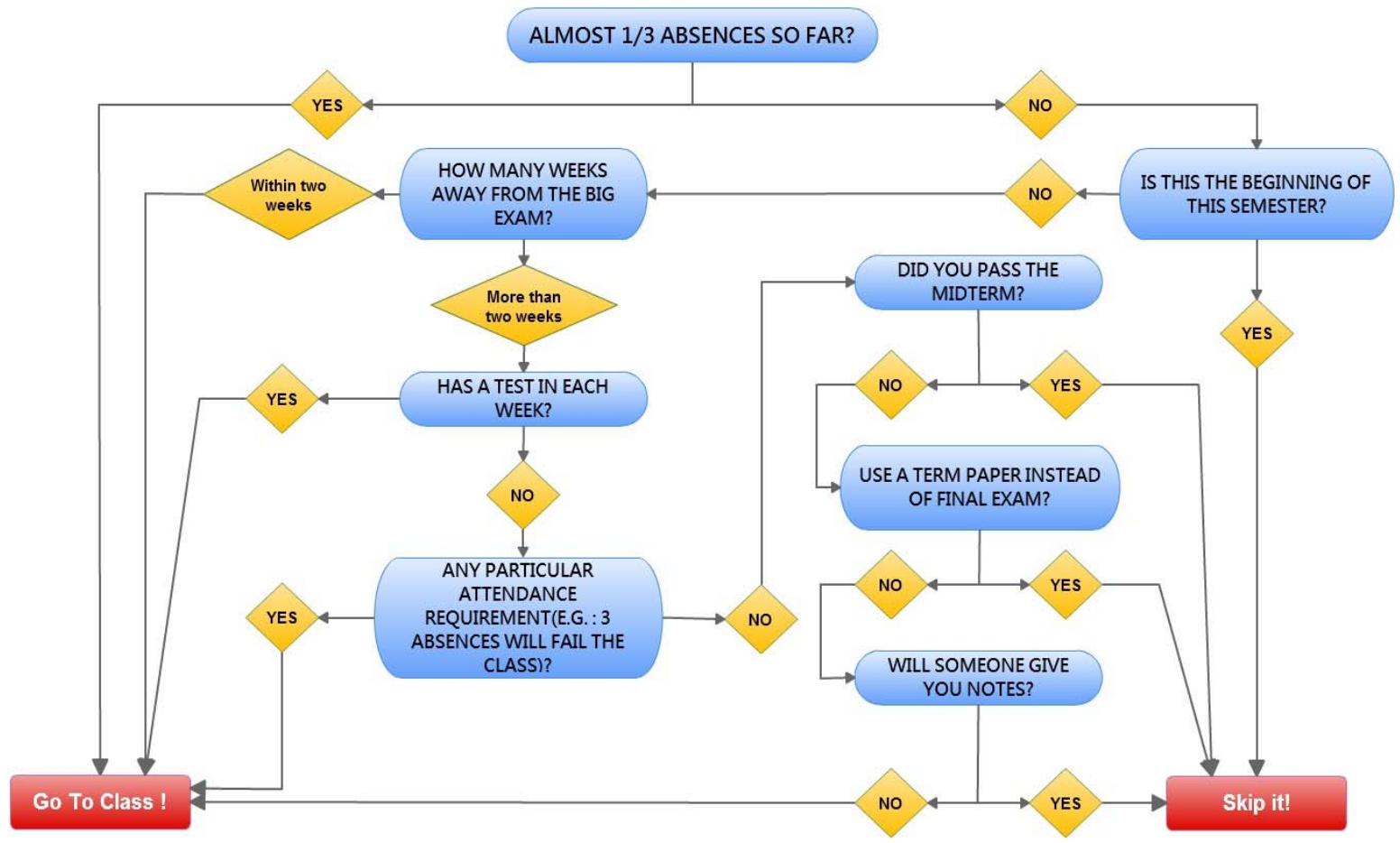

Fig. 2 The flowchart of "Skip Class". 


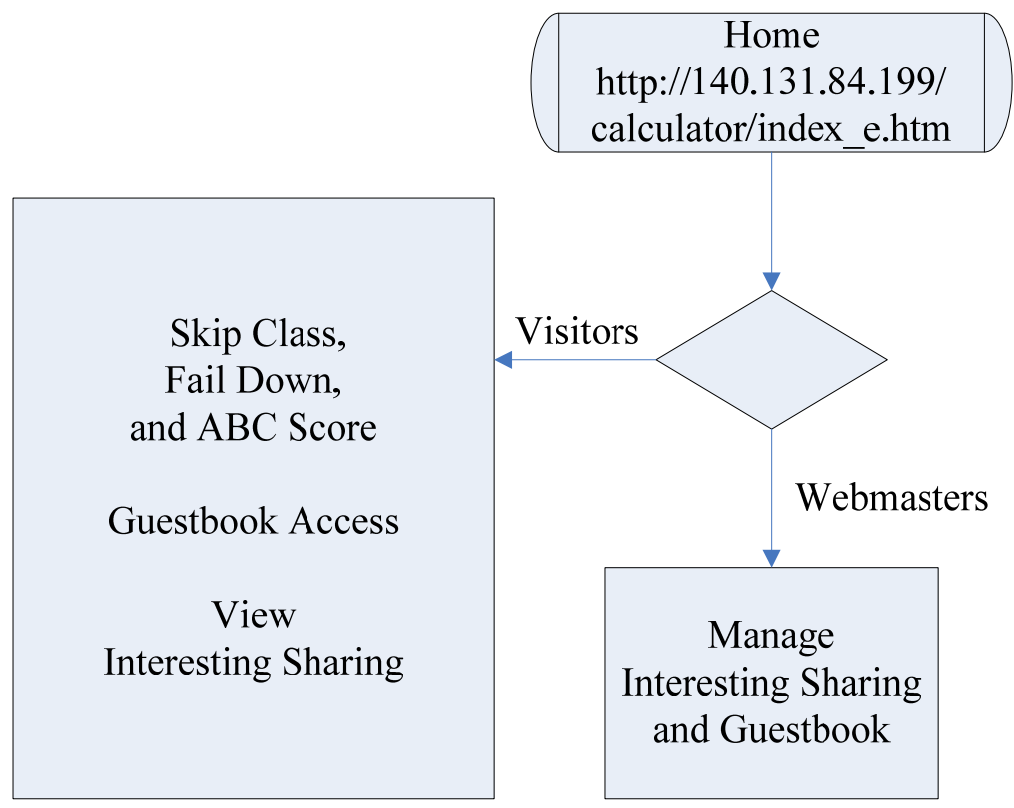

Fig. 3 The flow chart of using the healthy weight network.

on the day before big examination, and the student's GPA score). ABC Score is to calculate the students' GPA in which the students may realize that the consequence of skipping classes is more likely to get lower grades. "Guestbook" connects website users together by allowing users to share their personal experiences. "Interesting Sharing" shares the different stories of how students around the world go to school in many difficult ways. It also introduces the skipping class techniques and some interesting tools for writing punishment.

\subsection{The Flowchart for Using the Platform}

Fig. 3 is a flowchart of using the Learning Value website. Visitors are not only allowed to use the functions of "Skip Class", Fail Down”, and “ABC Score", but also allowed to read the article of "Interesting Sharing" and posting their messages and comments in "Guestbook" access.

Webmasters are also known as the website administrators of whom are responsible to answer questions as well as change and manipulate any comment or messages posted by users. Webmasters are also in charge of maintaining and developing the platform website.

\section{Platform Design, Management, and Maintenance}

The platform website is a source for making the decision of skipping classes and online GPA calculators. The website needs to be maintained regularly in order to keep it updated and trendy. More of the disadvantages of the online e-community management are that the users and enterprises have the lower search costs to easily compare the information from similar entities. Also, the users of the online community may expect more and more up-to-date information about products, orders, etc. [Fischer]. Therefore, the content of platform should be up-to-date and events on the website must be current.

Website visitors frequently contact webmasters directly via email or message board for answers to their inquiries. Webmasters are also known as the website administrators of whom are responsible to answer questions. Webmasters are also responsible for reviewing error reports and revising webpage bugs.

Protecting platform from losing data or moral reasons, the process of changing and manipulating any 
comment or messages posted by members as well as backup current data is a necessary step to severe consequences in potential security and legal battles.

\section{Future Work of Learning Value Website}

Expanding the popularity of Learning Value website will be continued to execute in order to increase visitors. One future objective is to expand popularity by raising the website search engine ranking. The technical aspects include containing the most important keywords from its corresponding page in the title bar and containing the most important keywords that potential customers would use to find this website on a search engine [Buresh]. Search engines pick up a lot of keywords and information on what people search for. Therefore, the analysis of message board's most important keywords used on the platform still requires future work.

It is important that visitors also find what they are looking for to avoid visitors giving up the research or leaving the website. Another future objective is perfecting the experience for users that navigate the platform.

In order to retain visitor interest and regular visits of users, yet another future objective of the platform is that the website should be always up-to-date and enhanced with state-of-the-art features, contents, and events.

\section{Conclusion}

According to research, five more absences would most likely lead to a decreased chance to graduate a particular educational institution [Middleerthnj]. The Learning Value website uses interesting themes such as "Skip Class", "Fail Down” and "ABC Score" to make students realize that skipping classes is more likely to get lower grades and at higher risks of obtaining no knowledge at all. It is toward lower chances to successfully graduate and direct waste of money for all those who have to pay for the education fund. For retaining visitor interest, the content of the platform website must be maintained regularly and always up-to-date.

\section{References}

[1] Buresh, S. 2007. "Four Tips to Increase Search Engine Ranking.” Medium Blue Search Engine Marketing.

[2] Fischer, D. 2002. "Textile Online: A Critical Overview." In International Textile Bulletin, 22-6.

[3] Kinsey, J. 2000. “A Faster, Learner, Supply Chain: New Uses of Information Technology.” American Journal of Agricultural Economics Article date: November 15, 2000.

[4] Middleearthnj. 2012. "The Impact of Skipping School." Accessed on October 16, 2012. https://middleearthnj.wordpress.com/2012/10/16/the-imp act-of-skipping-school.

[5] Slawski, B. 2000. "How a Search Engine may Expand Search Queries Based upon Popularity Measured by User Behavior." Internet Marketing and Search Engine Optimization (SEO) Services, Consulting, and Research. 